\title{
O uso da história oral na Psicologia: percepção de experiências individuais
}

\section{The use of oral history methodology in Psychology: perception of individual experiences}

\section{El uso de la historia oral en la Psicología: percepción de experiencias individuales}

\author{
Gabriela Campos Darahem* \\ Universidade de São Paulo - USP, Ribeirão Preto, São Paulo, Brasil \\ Milena Callegari Cosentino** \\ Universidade de São Paulo - USP, Ribeirão Preto, São Paulo, Brasil

\section{Gabriel Vieira Cândido***} \\ Universidade de São Paulo - USP, Ribeirão Preto, São Paulo, Brasil \\ Marina Massimi**** \\ Universidade de São Paulo - USP, Ribeirão Preto, São Paulo, Brasil
}

\begin{abstract}
RESUMO
Historiadores do presente utilizam diversas fontes para reconstruir 0 passado. Através da história oral podem, inclusive, elaborar os documentos que irão analisar. Este artigo apresenta três pesquisas que utilizaram a metodologia da história oral aplicada a três diferentes objetos: 1) o reconhecimento da importância de uma psicóloga brasileira, 2) a percepção do trabalho realizado por funcionários em instituições de educação infantil e 3) a ressignificação da experiência de um judeu sobrevivente da Segunda Guerra Mundial por seus descendentes. Ao dar enfoque às pessoas em seus contextos sociais e culturais próprios, cada trabalho produziu uma escrita histórica que valoriza diversos aspectos da cultura e das relações interpessoais, reconhecendo que o indivíduo é sujeito de um processo histórico. As três pesquisas evidenciam a fecundidade do uso da história oral para a valorização da memória dos entrevistados e para a elaboração de documentos que podem auxiliar na construção do presente e do futuro.
\end{abstract}

Palavras-chave: memória, história oral, psicologia.

\begin{abstract}
Researchers of recent history use different information sources to rebuild the past. Through oral history methodology, they can even produce the documents they will analyze. This paper presents three studies in which the authors applied the oral history methodology to three different subjects: 1 ) the acknowledgement of one Brazilian psychologist's importance, 2) the perception of the work accomplished by employees in childhood education
\end{abstract}


institutions and 3) the reframing of a Holocaust survivor's experience by his descendants. Focusing on people in their own social and cultural contexts, each work produced a historical writing that valorizes different aspects of culture and interpersonal relationships and recognizes that each person is the subject of a historical process. These studies point to the capability of the oral history methodology to valorize the memory of the interviewed people and also as a way to create documents that may help to build the present and future.

Keywords: memory, oral history, psychology.

\begin{abstract}
RESUMEN
Historiadores del presente utilizan diversas fuentes para reconstruir al pasado. Por medio de la historia oral, pueden, incluso, elaborar los documentos que serán analizados. Este artículo presenta tres investigaciones que utilizaron el método de la historia oral aplicada a tres distintos objetos: 1) el reconocimiento de la importancia de una psicóloga brasileña, 2) la percepción del trabajo realizado por empleados en instituciones de educación infantil y 3) el replanteamiento de la experiencia de un judío sobreviviente de la Segunda Guerra Mundial por sus descendientes. Cuándo se enfoca las personas en sus contextos sociales y culturales propios, cada investigación produce una escrita histórica que valora a diversos aspectos de la cultura y de las relaciones interpersonales, reconociendo que el individuo es sujeto de un proceso histórico. Las tres investigaciones muestran la fecundidad del uso de la historia oral para la valoración de la memoria de los participantes y para la elaboración de documentos que pueden auxiliar en la construcción del presente y del futuro.

Palabras clave: memoria, historia oral, psicología.
\end{abstract}

\title{
1 Introdução
}

Nas mais diversas áreas do conhecimento, estudos têm discutido a importância de se valorizar e resgatar a memória dos indivíduos que participaram ativamente de momentos sociais historicamente relevantes (Massimi, 2002; Schwarzstein, 2001; Von Simson, 2000). Especificamente, na Psicologia, modos de subjetivação podem ser analisados a partir de relatos acerca das experiências vivenciadas pelos mesmos.

Assim, o objetivo deste artigo é discutir como o uso do método da historia oral pode contribuir para analisar a percepção das experiências individuais. Isso será apresentado a partir de uma breve introdução teórica e, na sequência, de pesquisas realizadas com esta abordagem aplicada a três diferentes objetos: 1) como pessoas reconhecem a importância de uma psicóloga brasileira, 2) como percebem o trabalho que realizaram em instituições de educação infantil e 3) como os descendentes de um judeu sobrevivente da Segunda Guerra Mundial ressignificam esta experiência.

As pesquisas aqui apresentadas e descritas foram realizadas pelos próprios autores do artigo, que integram o Grupo de Pesquisa em História e Memória da Psicologia, da Faculdade de Filosofia, Ciências e 
Letras de Ribeirão Preto da Universidade de São Paulo, coordenado pela professora Marina Massimi.

Os autores fazem parte de um subgrupo do grupo anteriormente citado, que busca aplicar a metodologia da história oral a diferentes contextos dentro da área de Psicologia. Assim sendo, este artigo visa descrever como se deu a aplicação deste método nas diferentes pesquisas realizadas. Desta forma, a metodologia utilizada é de caráter qualitativo, mais precisamente descritivo.

\section{0 método da história oral}

Uma grande dificuldade encontrada pelo historiador refere-se ao acesso ao evento que está sendo investigado. Os historiadores não podem participar dos acontecimentos que estão investigando, de modo que todo acesso a informações relevantes para a escrita sobre o passado seria indireta.

Bloch (2001) enfatiza a importância dos testemunhos como uma maneira de acessar informações sobre o passado. Testemunhos de pessoas que viveram à época e que, supostamente, são os mais aptos a falar sobre o assunto; supostamente, porque toda história contada tem a influência da história pessoal do contador. Existe, ainda, o que o autor chamou de testemunhos escritos e não-escritos. Tais documentos materiais são vestígios do passado. São livros e artigos publicados ou não, cartas pessoais, jornais, boletins, revistas científicas, estatutos, premiações, dedicatórias, gravações, vídeos, e qualquer outro material produzido no passado e que possa trazer informações sobre o período que se deseja pesquisar. Com tais materiais se torna possível completar relatos que apresentam lacunas e conferir relatos suspeitos.

Apesar de haver muita discussão a respeito da validade das informações adquiridas a partir das fontes orais, não há razão para se considerar que as fontes escritas sejam puras, naturais, enquanto fontes orais sejam impuras porque são construídas. Fontes escritas também são.

O uso da história oral como fonte de dados para a pesquisa histórica tem levantado algumas questões sobre a formação e parcialidade das fontes, o papel do observador e a contextualização social e histórica de tais fontes. Contudo, isto não deveria ser um motivo de descrédito: "Como bem se tem assinalado, se trata de um problema comum a todas as fontes e hoje os historiadores consideramos sérios questionamentos com respeito a todas as formas de documentação" (Schwarzstein, 2001, p. 75).

Meihy e Holanda (2007), dizem que "História oral é um recurso moderno usado para a elaboração de registros, documentos, arquivamento e estudos referentes à experiência social de pessoas e 
de grupos. Ela é sempre uma história do tempo presente e também reconhecida como história viva" (p.17, grifos dos autores).

Para Frank (1999), o historiador, ao interrogar uma testemunha, constrói a sua fonte, sendo ele seu construtor e usuário. 0 testemunho, contudo, não é a história. É preciso refletir sobre as condições que o afetaram para entendê-lo, analisá-lo e inseri-lo na escrita histórica, entendendo os mecanismos pelos quais o testemunho se constrói e se constitui.

Apesar da distância temporal entre o testemunho e o evento narrado ser reconhecida como geradora de erros, em alguns casos 0 testemunho é insubstituível, sendo papel do historiador desmistificálo. Sendo assim, a memória não é uma construção de um evento, é sua reconstrução feita a partir de um distanciamento do momento rememorado e o momento do relato.

Dentre outros, a história oral procura dar voz às pessoas que na "história oficial", aquela que aparece na mídia e que se aprende na escola, são deixadas de lado. Schwarzstein (2001) exemplifica em seus trabalhos sobre histórias traumáticas:

A utilização de fontes orais tem sido um recurso muito adequado para esta investigação já que tem permitido conhecer o testemunho de indivíduos que sofreram na própria pele a guerra e o exílio, e, cuja participação, visão e narrativa autobiográficas do momento histórico que viveram teriam se perdido de outra maneira (p. 80).

Existem diversos tipos de técnicas de entrevista em história oral, por exemplo, a história de vida, o depoimento oral e a entrevista (Queiroz, 2008).

Na técnica do Depoimento Oral, que foi utilizada nas três pesquisas aqui apresentadas, o entrevistador lista uma série de temas a serem tratados durante a conversa e deixa que o participante discorra acerca destes temas. A lista, feita antes da realização da entrevista, exige que o entrevistador conheça bem a história e o participante para que os assuntos mais importantes sejam tratados. Embora a lista de temas deva ser a mesma para todos os entrevistados, podem surgir novos temas durante as entrevistas. Ou seja, “(...) na história de vida o colóquio é conduzido pelo narrador, que detém a condução do relato, enquanto nos depoimentos é o pesquisador que abertamente o dirige" (Queiroz, 2008, p.47) Como ressaltado anteriormente, não existe trabalho histórico que revele uma verdade absoluta. Portanto, a intenção da pesquisa que utiliza a história oral não é comprovar se os fatos relatados e seus pormenores são verdadeiros.

Não se deve criar a expectativa de que 
as memórias, construídas no jogo de perguntas e respostas como fontes de pesquisa, nos desvelem um real (...). A questão não é procurar a versão mais verdadeira, não é procurar nas fontes uma pista do que aconteceu na realidade, porque estamos entendendo que as memórias que pesquisamos, e que tratamos metodologicamente como discursos/práticas, são a realidade (Venson e Pedro, 2012, p.129, grifo das autoras).

Segundo Alberti (2012), os depoimentos não devem ser vistos como uma versão da história. Em vez disso, precisa ser reconhecido aquilo que os depoimentos de fato são. E para ele, as entrevistas gravadas

"documentam como o entrevistado, ou a entrevistada, quer ser visto(a), ou o que ele(a) quer falar para nós. Documentam também a relação de entrevista, que se estabelece entre nós, os entrevistadores, e eles(as), os(as) entrevistados(as). Documentam ainda a narrativa se constituindo" ( $p .164$ ).

A técnica da história oral caracteriza-se por ser uma narrativa linear e individual daquilo que o participante considera significativo. No entanto, tem-se em vista a obtenção de dados que ultrapassem o caráter individual e penetrem a coletividade à qual $o$ narrador pertence (Levy, 2006).

Busca-se uma relação de igualdade entre os pesquisadores e os participantes, para que estes fiquem à vontade para relatar o que quiserem. Os entrevistadores almejam manter o foco na escuta do indivíduo, daquele que relata, não se importando apenas com o conteúdo que estiver narrando, mas como estaria revivendo o que conta, observando como os entrevistados mantêm contato com as lembranças, bem como seus gestos e silêncios (Levy, 2006).

Para se ter acesso a este conteúdo tão próprio e intrínseco da pessoa, o historiador deve se situar entre uma objetividade necessária de seu objeto e sua própria subjetividade. Por meio das entrevistas, as fontes orais possibilitam que a memória seja erguida como um objeto histórico, possibilitando assim uma "história da memória" (Dosse, 2001, p. 95).

A favor deste tipo de fonte que é privilégio do historiador do presente, Schwarzstein (2001) afirma que "se trata de um método que cria seus próprios documentos, documentos que são por definição diálogos explícitos sobre a memória, com o entrevistado triangulando entre as experiências passadas e o contexto presente e cultural em que se recorda" (p. 73).

Não se trata de um simples registro do passado, mas sim de produtos culturais complexos, sob grande influência dos discursos e práticas do presente (a simples presença do entrevistador já exerce influência sobre o relato). Assim, todo relato sobre qualquer evento é subjetivo. 
Para a história oral, a memória é uma forma de evidência histórica e, portanto, deve ser analisada como tal. Considerando a memória como um conceito relacionado ao presente, na ação de recordar, as pessoas constroem um sentido para o passado e esta reflexão passa a ocupar um lugar fundamental para a ressignificação do passado que se recorda. Assim, considera-se que os dados obtidos nas entrevistas não só complementam, aprofundam e ilustram acontecimentos pouco estudados, mas mostram o significado que determinados acontecimentos tiveram para os entrevistados (Benadiba, 2007).

\section{0 uso do método da história oral}

Os trabalhos apresentados a seguir pertencem à área de História da Psicologia e utilizaram o método da história oral, embora tenham diferentes objetos de estudo. Todos eles foram desenvolvidos pelos próprios autores deste artigo, que integram o Grupo de Pesquisa em História e Memória da Psicologia, da Faculdade de Filosofia, Ciências e Letras de Ribeirão Preto, da Universidade de São Paulo.

A análise realizada neste artigo buscou evidenciar como indivíduos percebem suas experiências dentro de um mesmo contexto, como se apresentam e quais significados dão para a história narrada. O método da história oral propõe que o pesquisador se coloque em uma posição de igualdade em relação ao entrevistado. $O$ foco das entrevistas não é buscar a verdade sobre determinado assunto, mas a maneira que cada participante relata sua experiência. Desta forma, com o conjunto das entrevistas, é possível fazer uma escrita histórica que valorize a subjetividade dos entrevistados.

O primeiro estudo a ser apresentado mostra a possibilidade de conhecer a atuação de uma psicóloga brasileira que trabalhou ativamente em prol do desenvolvimento científico brasileiro, a partir da análise de relatos de pessoas que conviveram com ela. Em seguida, será apresentada uma investigação sobre a experiência de profissionais que trabalharam em instituições de educação infantil, a partir do relato dos mesmos. Uma terceira possibilidade de uso da história oral na psicologia será apresentada a partir da análise de relatos de familiares de um sobrevivente da Segunda Guerra Mundial, visando conhecer as diferentes maneiras de perceber a experiência potencialmente traumática. Todos os entrevistados autorizaram o uso de seus depoimentos por meio de um Termo de Consentimento Livre e Esclarecido (TCLE) elaborado de acordo com as normas do Comitê de Ética em Pesquisa da Faculdade de Filosofia, Ciências e Letras de Ribeirão Preto.

a) A História de uma pessoa 
Com o objetivo de conhecer a contribuição de Carolina Martuscelli Bori (1924 - 2004) para o desenvolvimento de uma cultura científica nacional, foram realizadas diversas entrevistas com profissionais que atuaram com ela. Assumindo que suas ações repercutiram não apenas na psicologia, área em que atuou desde o início de sua carreira, mas em vários ramos da ciência brasileira, conhecer o relato de pessoas que trabalharam com ela e, portanto, fizeram parte deste processo, se torna fundamental.

Para a realização das entrevistas foi solicitando ao entrevistado que relatasse atividades que desenvolveram com Carolina Bori, como a conheceram e como avaliam a contribuição dela para a ciência e para a psicologia. Toda entrevista foi iniciada com uma breve exposição sobre o processo de construção do problema de pesquisa e alguns pontos que o entrevistador gostaria que o entrevistado comentasse.

As entrevistas foram gravadas e transcritas. Em seguida, foi selecionado um trecho que as qualificassem. Alguns destes trechos foram utilizados neste artigo para explorar a maneira como cada depoente se apresenta, como apresentam Carolina Bori e como significam a própria história.

Como a área de história oral aponta, os relatos são cheios de detalhes e emoções já que, neste tipo de trabalho, a narrativa é feita por pessoas que viveram a história, são parte dela, participaram de momentos decisivos, de embates e do processo de construção da psicologia no Brasil e da cultura científica. Em alguns comentários dos depoentes, pode-se perceber o uso de termos que indicam um carinho por Bori ou mesmo uma maneira delicada e forte de considerar sua atuação. Alguns qualificadores como inspiração, origem, caminho, orientadora de direções e grande mestra indicam a influência que Bori teve no trabalho dos depoentes e o significado que os entrevistados deram para esta influência.

Outros depoentes apontam as diferenças entre a sua própria contribuição para a psicologia e a contribuição de Carolina Bori. Mencionando a forma como via a importância de Bori, destacou as diferenças pessoais e/ou metodológicas entre eles. Pode-se perceber algumas diferenças apontadas pelos depoentes que podem ser consideradas diferenças pessoais. "Ela não era tão fluente", "Sabia mandar" ou "ela achava que era irrelevante publicar" indicam maneiras de ver a forma que ela organizava e discutia o conteúdo das aulas, dividia tarefas ou publicava os resultados de pesquisa.

Há, também, diferenças do ponto de vista metodológico. Um dos entrevistados afirmou ter recebido um parecer positivo dado por Bori a um projeto que pretendia usar procedimentos muito diferentes aos da experimentação.

Um ponto em comum nos depoimentos foi a maneira como falam sobre suas próprias experiências com Carolina Bori em contextos de discussão de pesquisa. Algumas palavras que mostram a certeza que 
eles tem quanto à contribuição de Bori foram usadas pelos depoentes. O significado atribuído pode ser percebido no uso de expressões como "com habilidade" - como em "ela procurou, com habilidade, desenvolver e fortalecer a sua posição" ou "sempre", para descrever a preocupação maior de Bori - como em "Ela sempre teve uma dedicação às causas maiores da organização da universidade".

Além disso, alguns depoentes comentaram a surpresa que tiveram ao descobrir a religiosidade de Bori, outros destacaram as discussões que ela fazia com grandes personalidades políticas do país, como ministros e presidente. Vários entrevistados contaram a reação que tiveram quando foram alunos dela na disciplina "Psicologia Experimental", já no primeiro ano do curso de graduação em Filosofia (alguns se assustaram com a professora sério e brava, outros se admiraram com a área que ela apresentava). Comentam sua dificuldade com as palavras ("Era um pouco entrecortada, ela parava, pensava um pouco, falava um pouco assim aos arrancos").

Por fim, de acordo com os relatos, Carolina Bori teria sido uma grande incentivadora da pesquisa, em qualquer área que fosse. Alguns assuntos pouco explorados na literatura também se tornaram conhecidos, de acordo com a avaliação de cada um dos entrevistados. Sabe-se da ida de Carolina Bori para a FFCL Rio Claro, porém pouco se falava a respeito. Com as entrevistas pôde-se conhecer os motivos de Bori ir para lá. Além disso, mais que Análise Experimental do Comportamento, o laboratório de Rio Claro teria tido uma grande importância para a Psicologia Experimental no Brasil, já que importantes pesquisadores se interessaram pela área estudando neste laboratório, continuaram sua formação e acabaram formando outros pesquisadores.

Com o método utilizado está sendo possível reunir documentos e registrar uma parte da história da psicologia e das ciências no Brasil. Após organização de todo o material coletado, seu acesso poderá ser feito por toda a comunidade acadêmica.

\section{b) A História de uma Instituição}

As instituições investigadas nesta pesquisa foram as Escolas Municipais de Educação Infantil (EMEIs) da cidade de Ribeirão Preto. Em algumas cidades, as EMEls têm origem nos Parques Infantis (PIs), que foi um tipo de instituição, idealizado pelo escritor Mario de Andrade, quando Diretor de Cultura da cidade de São Paulo. O escritor via as crianças como portadoras de cultura, e pensou no PI como um espaço onde as crianças, filhos de 3 a 14 anos do operariado paulistano, pudessem ser, de fato, crianças, imersas na cultura brasileira (Faria, 1999).

O modelo de PI se espalhou por outros municípios e deu origem à rede pública de educação infantil da cidade de São Paulo e de muitas 
outras cidades do interior do estado, inclusive Ribeirão Preto, cidade onde foi realizada a pesquisa. Contudo, a concepção, o espaço físico e a rotina do PI eram diferentes do estilo das atuais Escolas Municipais de Educação Infantil (EMEls). Os PIs, para não se tornarem mera reprodução do modelo escolar, davam valor ao aspecto lúdico, tão importante na infância: os jogos tradicionais infantis e as brincadeiras. E no entanto, a grande maioria das EMEIs atuais, se tornaram apenas uma etapa preparatória para a vida escolar.

A pesquisa buscou obter informações a respeito das impressões que profissionais destas escolas têm sobre as mudanças que ocorreram ao longo do tempo, seja na rotina escolar ou na estrutura física das escolas; bem como saber que papel tais profissionais atribuem a este tipo de instituição no decorrer dos anos. Os entrevistados foram quatro professores e oito funcionários veteranos e/ou aposentados de EMEIs antigas da cidade. As entrevistas foram realizadas em horários e locais definidos pelos participantes para deixá-los o mais à vontade possível com a situação de entrevista.

De modo geral, houve dificuldade para encontrar documentos nos arquivos das instituições. Contudo, enquanto os documentos, escassos, foram de pouca ajuda na pesquisa, as entrevistas realizadas foram ricas e permitiram a elaboração de um perfil da atual pré-escola da cidade.

Mais do que apresentar seus pontos de vista sobre as instituições onde trabalharam ou trabalham, os participantes da pesquisa mostraram a importância da experiência de trabalhar nesses espaços, em suas vidas. A maioria dos entrevistados (estoquistas, professores e cozinheiras, funcionários de limpeza) destacou a importância de seu trabalho (em sala de aula ou não) para a educação e cuidado das crianças. Mas alguns ainda buscam reconhecimento pelo trabalho que realizam, como por exemplo, uma das cozinheiras que reclamou do fato de não ser reconhecida na rua pelos pais da EMEI por passar tempo demais dentro da cozinha, sem contato com outras pessoas que não as crianças e outros funcionários.

Muitos funcionários iniciaram sua carreira nas EMEIs sem ter certeza que era esse o emprego que queriam ter. Uma professora contou que voltava chorando da escola todo dia nos primeiros meses, por não saber o que fazer com as crianças. Outra cozinheira relatou que chorava quando voltava para casa, por não saber lidar com a pressão e preconceito que sofria da diretora. Embora tenham relatado muitos percalços durante os anos que passaram nas escolas, os entrevistados classificaram o trabalho como gratificante (seja por verem as crianças gostando da comida que fazem, seja por vê-las aprendendo e se desenvolvendo ao longo do ano, etc.). Muitos demonstraram apego pelo local de trabalho, considerando seus colegas de trabalho como família, como o caso de um funcionário que trabalhou por mais de 30 anos na escola e diz ter se aposentado 
apenas porque foi obrigado (ao atingir a idade de 70 anos) e a estoquista que teve de se aposentar compulsoriamente devido a um acidente de trabalho.

Por terem demonstrado apego e carinho pelo local de trabalho e também pelo serviço que desempenhavam/desempenham em suas respectivas escolas, muitos dos funcionários declararam-se contra a prática atual de contratação de funcionários terceirizados, porque estes geralmente passam menos tempo na função e não criam vínculos com a escola.

Esta pesquisa buscou colocar em prática o elemento da metodologia da história oral de dar voz aos que geralmente não a tem (Von Simson, 2000), já que eles são os "guardiões da memória" das EMEIs. Assim, a maior contribuição que esta pesquisa oferece à história da educação infantil municipal de Ribeirão Preto é a valorização das memórias dos funcionários e professores das EMEIs. São eles os responsáveis pelo funcionamento das escolas no dia a dia, passam grande parte de sua vida dentro delas e por isso respeitar e zelar pela história destas instituições significa respeito e valorização destes profissionais e suas próprias histórias.

\section{c) A História de uma família da comunidade judaica}

A terceira pesquisa apresenta os resultados obtidos com objetivo de analisar as repercussões da experiência e da memória vivida e significada de uma família. Mais especificamente, buscou-se avaliar a vivência e elaboração do trauma de um judeu sobrevivente da II Guerra Mundial e a percepção de seus descendentes a este respeito. Como não há muitos estudos sobre as repercussões de acontecimentos traumáticos na vida dos descendentes, as entrevistas realizadas com os filhos e netos deste judeu sobrevivente foram ao encontro de uma perspectiva pouco explorada e carente de pesquisa. Pelo fato da maioria dos descendentes ter nascido no Brasil e todos serem fruto de união entre judeus e não judeus, visou-se verificar se eles permaneceram preservando as tradições culturais judaicas. Além disso, a entrevista do sobrevivente foi comparada com a de seus descendentes, buscando-se analisar as diferentes perspectivas de indivíduos que viviam em um mesmo contexto e cultura (Brasil), mas que vivenciaram diferentes momentos históricos.

Os participantes foram contatados pela Sociedade Israelita de Ribeirão Preto (SIRP), da qual o judeu sobrevivente da II Guerra era membro ativo. Para realizar as entrevistas foi utilizado o método da historia oral. A pesquisadora buscou contato anterior com os participantes e foi até suas casas, visando um ambiente e uma relação menos formais, como é a proposta da história oral. Todos os relatos foram gravados e transcritos na íntegra, pela própria entrevistadora. 
Ao se delimitar um tema, pelo método da história oral temática, perguntou-se para o sobrevivente sobre sua história de vida e se ele achava que a experiência da II Guerra Mundial teria alguma influência em sua vida hoje. Aos descendentes foram apresentadas as seguintes perguntas: "Seu pai/ avô costumava contar as histórias da vida, da guerra? Como é para você saber da história de seus pais/avós? O que isso significa para você? O que você sente quando lembra?", mas os participantes tinham liberdade para contar sobre o que quisessem. Seguem as principais características dos participantes. Apenas as iniciais de seus nomes serão apresentadas, visando preservar a identidade dos entrevistados.

F.H.: judeu sobrevivente da II Guerra mundial. No momento da entrevista tinha 95 anos e era membro ativo da Sociedade Israelita de Ribeirão. Entrevista realizada em 06/10/2009.

A.H.: primeiro filho de F.H. Nasceu em 1950 em Belgrado, na Sérvia (ex-I ugoslávia). Entrevista realizada em 21/12/2009.

V.I.H.T.: segunda filha de F.H. Nasceu em 1957, em Franca (SP). Entrevista realizada em 16/10/2009.

T.H.T.: Neta de F.H., primeira filha de V. Nasceu em 1987, em Itajubá (MG). Entrevista realizada em 16/10/2009.

I.H.T.: Neto de F.H., segundo filho de V.I.H.T. Nasceu em 1993, em Ribeirão Preto (SP). Entrevista realizada em 16/10/2009.

Os temas mais recorrentes nas entrevistas foram: o valor e as influências da experiência do sobrevivente na II Guerra Mundial; o trabalho e a vida cotidiana como forma de elaboração; a cultura "entre linhas", que se dá pelo gosto e dedicação pelos estudos, característica cultural implícita, que muitas vezes passa despercebida, mas que é presente e é transmitida ao longo das gerações; características pessoais que acreditam ser "herdadas" pela história de vida do sobrevivente; as diferenças de cultura e religião; o poder de influência da sociedade; a adaptação como estrangeiro; o lazer como forma de preservação da pessoa (esporte) e a crença que "o tempo cura tudo".

Percebe-se que, apesar do tema ser de alguma forma conduzido pela pesquisadora, o conteúdo dos relatos apresenta grande diversidade, evidenciando a liberdade dos participantes em contarem o que consideram importante. Esta flexibilidade é proporcionada pela técnica da história oral.

A análise qualitativa dos dados foi feita sob a perspectiva da memória coletiva de Maurice Halbwachs (2006): o indivíduo possui uma memória individual e uma coletiva, sendo a memória uma construção social e um fenômeno coletivo e, em parte, modelada pela família e pelos grupos sociais. A história de vida do sobrevivente e suas experiências foram percebidas e assimiladas de maneiras diferentes 
pelos seus descendentes, cada um tendo uma percepção singular dos eventos relatados.

Os resultados obtidos foram apresentados em uma reunião agendada na Sociedade Israelita de Ribeirão Preto, com a presença dos membros desta sociedade e de alguns dos participantes. Assim, cumpriu-se o compromisso social, presente na técnica da história oral, gerando documentos e ajudando indivíduos e a própria comunidade a conhecerem e reconhecerem parte de suas histórias.

\section{0 método da história oral na Psicologia}

A breve descrição das três pesquisas evidencia a fecundidade do uso da história oral para a valorização da memória dos entrevistados. Elas enfocam pessoas em seus contextos sociais e culturais próprios (Schwarzstein, 2001). Valendo-se do método da história oral, cada um dos trabalhos produziu uma escrita histórica que valoriza diversos aspectos da cultura e das relações interpessoais, reconhecendo que o indivíduo é sujeito de um processo histórico. Sem o depoimento das pessoas que participaram da história, diversos pontos do passado poderiam ser ignorados em importantes decisões no presente. Desta forma, os relatos geraram materiais que podem auxiliar na construção do presente e do futuro.

Uma das características da história oral é a possibilidade de se criar não apenas conhecimento, mas também documentos (Bloch, 2001; Meihy e Holanda, 2007). Aqui, tem-se o exemplo da produção de documentos acerca da Professora Carolina Bori, das contribuições de funcionários e professores para a educação infantil em Ribeirão Preto e das elaborações das experiências de uma família da comunidade judaica. Percebe-se que, com a valorização da memória dos entrevistados, novas informações puderam ser coletadas, dando um olhar atento às participações individuais na construção da história.

Trabalhos como estes contribuem não apenas com a história da psicologia e educação infantil, mas, na medida em que as entrevistas passam a constituir centros de memória ou arquivos, tornam-se importantes registros da memória nacional e/ou local. O arquivamento também é uma forma de valorizar a memória dos que colaboraram com o estudo e, ao mesmo tempo, de contribuir para a realização de novas investigações acerca dos temas apresentados.

\section{Considerações finais}

A história oral é uma metodologia que procura 
registrar - e, portanto, perpetuar - impressões, vivências, lembranças daqueles indivíduos que se dispõem a compartilhar sua memória com a coletividade e, dessa forma, permitir um conhecimento do vivido muito mais rico, dinâmico e colorido de situações que, de outra forma, não conheceríamos (Matos \& Senna, 2011).

Como toda metodologia utilizada em pesquisas históricas, a história oral tem suas limitações. A escrita histórica resultante de uma pesquisa que se vale de tal método não tem apenas a delimitação (necessária) do tempo histórico a ser investigado. Ela também é limitada pelo grupo de entrevistados escolhidos para participar da pesquisa.

Em cada depoimento, os entrevistados apresentam sua própria subjetividade e falam sobre determinado evento de uma maneira diferente. Com isso, o conjunto de entrevistas forma um conjunto de olhares sobre um determinado fenômeno ou período histórico. Isto permite ao pesquisador reconstruir determinado evento a partir de vários pontos de vista. Cabe ao pesquisador fazer uma leitura cuidadosa de cada documento produzido pelas entrevistas, reconhecendo que elas, por si, não representam a história como aconteceu.

\section{Referências}

Alberti, V. (2012). De "versão" a "narrativa" no Manual de história oral. História Oral, 15(2), 159 - 166.

Benadiba, L. (2007). Historia Oral. Relatos y Memorias. Editorial Maipue, Buenos Aires.

Bloch, M. (2001). Apologia da História ou o Ofício do Historiador (L. M. Schwarcz \& A. Telle Trad.). Rio de Janeiro: Jorge Zahar Editor. (Obra original publicada em 1997).

Dosse, F. (2001). A história à prova do tempo: da história em migalhas ao resgate de sentido (I. C. Benedetti Trad.). Editora UNESP: São Paulo.

Faria, A. L. G. (1999). A contribuição dos parques infantis de Mário de Andrade para a construção de uma pedagogia da educação infantil, Educação e Sociedade, 20(69), 60-91.

Frank, R. (1999). Questões para as fontes do presente (p. 7-38). In A. Chauveau, \& Ph. Tétard (Orgs.). Questões para a história do presente (I. S. Cohen, Trad.), pp. 103 - 118. Bauru : EDUSC.

Halbwachs, M. (2006). A Memória Coletiva (B. Sidou, Trad.). São Paulo: Centauro. (Obra original publicada em 1968).

Levy, S.D. (2006). Oito relatos SOBRE VIVER antes, durante e depois do Holocausto por homens e mulheres acolhidos no Brasil. Rio 
de Janeiro: Relume Duramá: Federação Israelita do Rio de Janeiro.

Massimi, M. (2002). Memória e história na história da psicologia: dois exemplos de produção de documentos, Memorandum, 2, 2-12. Recuperado em 15 de setembro, 2011, de http://www.fafich.ufmg.br/ memorandum/artigos02/massimi0 2.htm

Matos, J.S., \& Senna, A.K. (2011). História oral como fonte: problemas e métodos. Historiæ, 2(1), 95-108.

Meihy, J.C.S.B., \& Holanda, F. (2007). História oral: como fazer, como pensar. São Paulo: Contexto.

Queiroz, M.I.P. (2008). Relatos orais: do "indizível" ao "dizível". In C.T. Lucena, M.C.S.S. Campos, \& Z.B.F. Demartini (Orgs.). Pesquisa em Ciências Sociais: olhares de Maria Isaura Pereira de Queiroz. (p. 35-77). São Paulo: CERU.

Schwarzstein, D. (2001). História oral, memória e histórias traumáticas. História Oral, 4, 73-83.

Venson, A.M., \& Pedro, J.M. (2012). Memórias como fonte de pesquisa em história e antropologia. História Oral, 15 (2), 125139.

Von Simson, O.R.M. (2000). Memória, cultura e poder na sociedade do esquecimento. O exemplo do Centro de Memória da UNICAMP. In: L.M. Faria Filho (Org.). Arquivos, Fontes e Novas Tecnologias: questões para a história da educação (p. 63-74). Campinas: Autores Associados.

\section{Endereço para correspondência \\ Gabriela Campos Darahem}

Universidade de São Paulo

Departamento de Psicologia

Faculdade de Filosofia, Ciências e Letras de Ribeirão Preto

Av. Bandeirantes, 3900, Monte Alegre, CEP 14040-901, Ribeirão Preto - SP, Brasil

Endereço eletrônico: gabidarahem@gmail.com

\section{Milena Callegari Cosentino}

Universidade de São Paulo

Departamento de Psicologia

Faculdade de Filosofia, Ciências e Letras de Ribeirão Preto

Av. Bandeirantes, 3900, Monte Alegre, CEP 14040-901, Ribeirão Preto - SP, Brasil

Endereço eletrônico: milena_callegari@yahoo.com.br

\section{Gabriel Vieira Cândido}

Universidade de São Paulo

Departamento de Psicologia

Faculdade de Filosofia, Ciências e Letras de Ribeirão Preto

Av. Bandeirantes, 3900, Monte Alegre, CEP 14040-901, Ribeirão Preto - SP, Brasil

Endereço eletrônico: gaviecan@gmail.com

\section{Marina Massimi}

Universidade de São Paulo

Departamento de Psicologia 
Faculdade de Filosofia, Ciências e Letras de Ribeirão Preto

Av. Bandeirantes, 3900, Monte Alegre, CEP 14040-901, Ribeirão Preto - SP, Brasil Endereço eletrônico: mmassimi3@yahoo.com

Recebido em: 14/05/2014

Reformulado em: 17/09/2014

Aceito para publicação em: 08/11/2014

\section{Notas}

* Possui licenciatura plena em Pedagogia pela Faculdade de Filosofia, Ciências e Letras de Ribeirão Preto da Universidade de São Paulo e mestrado em Psicologia pela mesma instituição.

** Mestre em Psicologia pela Faculdade de Filosofia, Ciências e Letras de Ribeirão Preto da Universidade de São Paulo (USP). Atua como Psicóloga na Clínica Terapêutica Unitas, Ribeirão Preto - SP e no CAPS I da Prefeitura Municipal de Brodowski - SP. Experiência no ensino de História da Psicologia Contemporânea.

*** Mestre em Psicologia Experimental: análise do comportamento pela PUC-SP, doutor em Psicologia pela Faculdade de Filosofia, Ciências e Letras de Ribeirão Preto da Universidade de São Paulo e professor do curso de Psicologia da Universidade do Oeste Paulista (Unoeste).

**** Professora Titular e trabalha junto ao Departamento de Psicologia e Educação na Faculdade de Filosofia Ciências e Letras da Universidade de São Paulo, Campus de Ribeirão Preto, Brasil. Especialista na área de História das Ideias Psicológicas na Cultura Luso-Brasileira. 